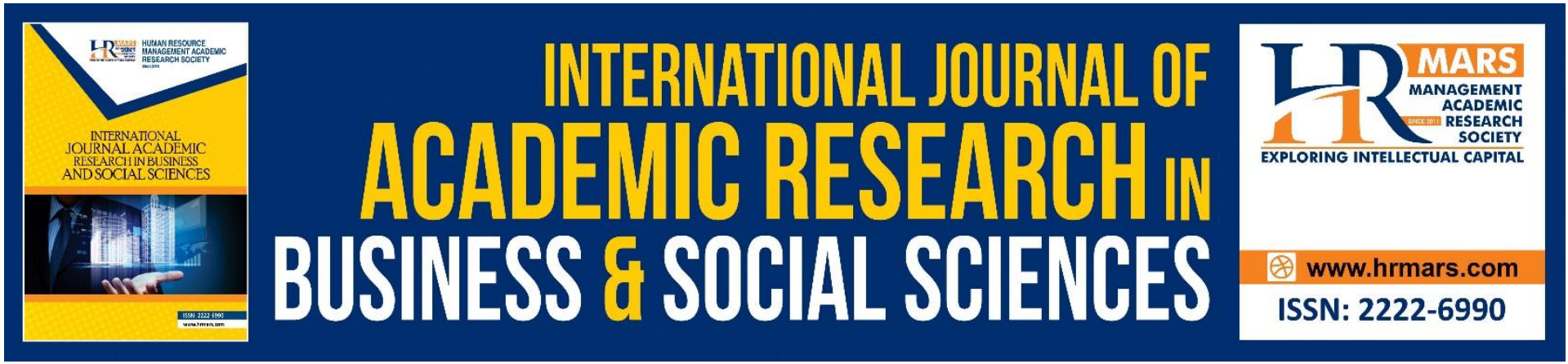

\title{
Racial Representation in Western Animation: A Media Influenced By History and Society
}

Nur Liana Mohd Redzuan Roy, Nora Edrina Sahharil

To Link this Article: http://dx.doi.org/10.6007/IJARBSS/v10-i12/8355

DOI:10.6007/IJARBSS/v10-i12/8355

Received: 21 October 2020, Revised: 17 November 2020, Accepted: 30 November 2020

Published Online: 19 December 2020

In-Text Citation: (Roy \& Sahharil, 2020)

To Cite this Article: Roy, N. L. M. R., \& Sahharil, N. E. (2020). Racial Representation in Western Animation: A Media Influenced By History and Society. International Journal of Academic Research in Business and Social Sciences, 10(12), 558-574.

Copyright: (c) 2020 The Author(s)

Published by Human Resource Management Academic Research Society (www.hrmars.com)

This article is published under the Creative Commons Attribution (CC BY 4.0) license. Anyone may reproduce, distribute, translate and create derivative works of this article (for both commercial and non-commercial purposes), subject to full attribution to the original publication and authors. The full terms of this license may be seen

at: http://creativecommons.org/licences/by/4.0/legalcode

Vol. 10, No. 12, 2020, Pg. 558 - 574

http://hrmars.com/index.php/pages/detail/IJARBSS

JOURNAL HOMEPAGE

Full Terms \& Conditions of access and use can be found at http://hrmars.com/index.php/pages/detail/publication-ethics 


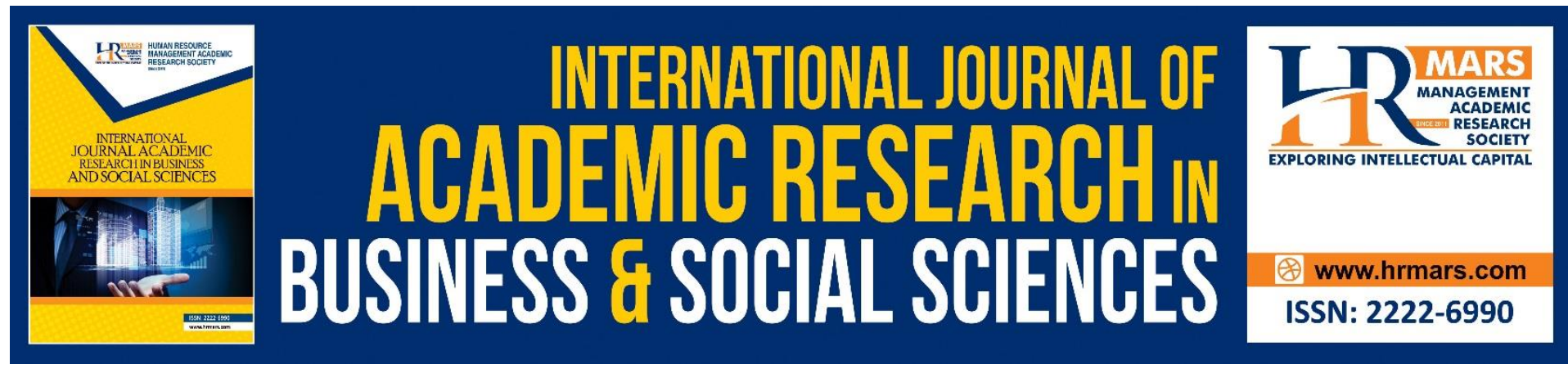

\title{
Racial Representation in Western Animation: A Media Influenced By History and Society
}

\author{
Nur Liana Mohd Redzuan Roy, Nora Edrina Sahharil \\ Faculty of Film, Theatre and Animation, Universiti Teknologi Mara \\ Email: edrina@uitm.edu.my
}

\begin{abstract}
In this essay, I explore the history behind racial representation in Western animation and how the flow of time and the people behind these portrayals have brought change into these representations. My argument is that history has influenced the racial representations and perception of society towards people of colour and modern animation and animators have changes these representations drastically. The focus of the argument has been to analyse prior animators' works in the past that have led to unsavoury representations, changes taken by modern animators to change these representations and the importance behind having both the older portrayals and newer portrayals in western animation history. The method I use in this essay is a close reading of historical agendas in relation to the past's representations and current representations, and an analysis of these animations' portrayals of racial characters. I employ historical and sociological criticism as a framework to the analysis. The reading offered in this essay also highlights the importance of having every type of representations as each of them plays an important role in the development of future representations in western animation.
\end{abstract}

Keywords: Animation, History, Portrayal, Representation, Western

\section{Introduction}

The world has now become radically different from the past as it could no longer be considered as mostly homogenous with the migration of people to other locations in search for a promising future or an attempt to seek refuge. Paul Hodkinson established that the "long-term and more recent patterns of migration have resulted in a situation where many countries have considerable ethnic diversity within their populations" $(2017$, p. 222$)$. This is most common in the Western parts of the world, due to the perception of job opportunities for migrant families as well as an unsettling past concerning the colonization of the Native Americans and with it, the enslavement of the African people that brought forth the diversity in society today. While countries and continents are becoming flooded with people differing in skin colour, beliefs and cultural heritage, the word 'diversity' has now either become a source of strength for the people or a source of conflict amongst them. The word, while harmless, has been used on multiple occasions, especially during the socio-political turmoil both in the United States of America and Britain, due to their leaders and the decisions made by the political heads in both nations. With the colonization of coloured people in the past, 
propaganda and stereotypes have painted them in a negative light which has carried on even to this day. Racial representation as one of the most debated issues in western countries, in short, is the portrayal of characters from different races or ethnicities in media. The topic is often considered a sensitive subject due to the racism that is still prevalent as some are still holding on to belittling views of those they deemed inferior. The issue of diversity has also trickled into the entertainment media, with it being one of the largest income sources for the States, prompting many people from minority groups along with their allies to question large entertainment companies of the lack of racial representation on screen, be it in films, televisions and animated media.

Animated media in the west is a unique subject to study as it is a media that started when people were interested in taking the Persistence of Vision theory a step further, developing into moving images. In terms of stylization, the rubber-hose style during the Disney and Fleischer eras then shifted to a much more anthropomorphic look, dominated by Disney in later years. However, the stylization of Western animation has now shifted into a more diverse range of looks to cater to the multitude of audience demographics that have now tuned in to animation as a source of entertainment. However, even with the creative liberty that comes with animation especially in creating characters and stories, there are still limitations of racial character design and cultural representation. There is an obvious lack of racially diverse casts and proper representation in Western animation which has earned the ire from people of colour, specifically the younger adults in today's day and age. The small number of active coloured characters coupled with the fact that there is an increase of white and anthropomorphic characters in comparison have caused outrage as people's representations are seen as minimal, lacklustre or stereotypical, and even borderline offensive in minor cases. Even with the existing characters available, these characters give part of the audience an unsettling feeling as the representation they are forced to see are uncomfortably stereotypical, especially coming from Caucasian creators. The appearance of coloured characters in some shows are borderline racist as some of them are portrayed as these caricatures that colonizers have either placed onto them in the past or their white counterparts have labelled them in more modern times.

These issues are speculated to have been because of past animations and cartoons, with racial characters becoming the most known caricatures of the time as Paul Wells expressed in his book, "The issue of the representation of race in animation is essentially clouded by the self-evident racism of cartoon caricaturing from the early teens of the century to the late $1940 s^{\prime \prime}(2015$, p. 215). My thesis is that the lack of racial representation within the current Western animation is due to the media which has been steeped in political and racial turmoil, made worse with the existence of the "coloniser" mindset when it comes to media. In historical context, due to wars, colonialism and slavery, some imageries of the minority groups were created to depict certain cultures from the perspective of the white colonialists and slave-owners, resulting in racist caricatures and reducing these races to mere entertainment in the eyes of their Caucasian counterparts. This was also done to further debilitate their credibility and further paint them in a negative light, ensuring that the Caucasians would not side with the minorities in order to uphold power over them. In this essay, I will show that the western animation in the past and the in the current decade is heavily influenced by the country's history towards minority groups thus heavily influencing the depiction or lack of it in the media. These negative portrayals also cloud the minds of viewers to believe these propagandist and racist views on people of colour. I will also argue that the emergence of more diverse cast in modern Western animation is heavily influenced 
by people within the industry who have taken a stand in including people of colour and spreading a more positive message compared to the past. These creators' awareness of the racial turmoil in their country and lack of representation has allowed them to be the backbone of the new age of animation where inclusivity is represented well without the negative connotations that come with cultural identity and skin colour. Lastly, there is an importance in these portrayals, whether it be negative from the historical accounts, or positive from the representations in modern times, and the impacts both kind of representation can help shape the future for a more diverse animation industry, whether the people and the industry players realize it or not. The awareness of the subject and the lack of erasure of previous mistakes will continue to not only shape the industry, but also society's views towards these representations and continued change of it as well.

The conversation of racial representation can be argued to have first appeared with the appearance of minstrels that was translated visually in old-style animation such as the black and white animated media often produced by Disney and Fleischer. Some of the character were involved in the minstrelsy scene as noted by Sammond $(2015$, p. 3) such as Mickey Mouse's character in the short Mickey's Mellerdrammer (Disney, 1933) where Mickey Mouse who was a minstrel, blackened his face in the short. These minstrelsies were to entertain the masses and were based on the fantasy the white people had of recalcitrant African American slaves or of the "free man". Lehman also brought up that, "In addition to blackface designs for metamorphosis gags and for animal characters, studios also used popular songs to accompany cartoon gags that drew laughs at the expense of the African Americans" (2009, p. 14). These acts of blackface and minstrelsy had a huge impact on the animation industry during the past, and it played a major role in shaping the humour of the people in that particular era. However, the years of these minstrelsy in animation were not too far from today, thus these animations have shaped the viewpoint people had towards minorities that is even prevalent today. It has also shaped the comedic nature of racial portrayals, and due to this, some portrayals are highly uncomfortable for viewing, especially during a political turmoil.

As opposed to today's animation, a lot of these body of works are heavily emotional and growth focused, aiming at not only children in its content, but towards adults as well, in the message behind these animated works. Some of the modern works, while not heavily focusing on the topic of race itself, has depicted fleshed out, multidimensional characters, allowing for anyone watching the animations to relate to the characters. When the characters are created with the intention of talking about race and culture, modern animation has taken the step to show these characters in a more positive light, going against the stereotypes often associated with their skin colour and cultural heritage. As an example, the cartoon Craig of the Creek shows a healthier, black family dynamic with men who are sensitive and familyoriented unlike the stereotypical brutish selfish people black men were labelled as. Not only that, but the show also shows emotionally intelligent kids, having a healthy communication with parents and vice versa. While the time difference between these animated medias are not so distant, it showcases the same theme; a focus on the topic of African American imagery within these works. My aim is to show that even though older works and newer works share the same 'themes', they are not necessarily one in the same, even if both medias have been influenced by history and the people along the years. A creation of a truly diverse cast of characters with proper representation could not only change the viewpoint some people have against the minorities but it can empower people to accept and embrace their cultural heritage and ethnicity. 


\section{Methodology}

The method I have used as a starting point has been a close reading of historical texts pertaining to the history of Western animation and the history of the country as an influence to the development of the animated media in the past. Aside from that, an analysis of past animated works in the 1930s and above in comparison to much newer animated works in the recent decades will be studied in terms of its relation to the history and its people that may have heavily influenced these works and shape them to be what they are then and today.

Racial representation in animated media is somewhat brought up in discussions as fans are often confused by the lack of diverse cultures and ethnicities colouring their screens, but the lack of these particular characters may not lie within the creators but within the society's wants and opposition. Creators today have now begun experimenting with story and characters to cater to the more diverse audience, delivering fiction to fit the future. A number of secondary resources will be used to further comment on Western animation and its relation to the black minstrelsy as well as its propagandist or racist viewpoint on characters of other ethnicities, and bring forth the difference between the past that once seek to separate and the future that seek to unite.

\section{Historical Context of Racial Representation in Animation}

In this section I will explore the history behind racial representation in Western animation. First, I will study the history behind Western colonization and the treatment minorities were forced to go through as the result or said colonialism, war and enslavement of the Africans, and whether these prior acts of supposed superiority influenced the racist views within the upcoming animation scene. Then I will examine the modern animation scene and how its viewpoints have changed throughout the years.

It can be surmised and assumed that the first form of racial representation in animation appeared in the older animations, when it was limited to the two main studios of Disney and Fleischer. The characters portrayed were during the black and white era set in the 1930s, where racism and racial discourse were prevalent and borderline vicious towards minorities. According to historians and personal accounts of the era, the whites and the blacks were not on good terms. Especially in American lands, white people insisted that their rights should be upheld and separated from the blacks, and some blacks have taken to riots and started to defend their own rights within the country. Whites in blackface would perform an act called blackface minstrelsy for the Caucasian society, placing forth a caricaturized image of the black body, diminishing them as fools and jokers. Animated minstrelsy appeared in the form of popular characters such as Mickey Mouse, Felix the Cat and many more, and "performed a desirable and humorous irrationality that begged both admiration and punishment" (Dobson et al, 2018, p. 221). When the minstrelsy scene stopped, animation took over

its place.

In the 1930s, animation was becoming more known and were considered entertainment during tougher times. The imageries portrayed in the animations were unsavoury, depicting people of other races in an offensive manner. However, not all depictions of ethnic people were done purposefully; most were done in a 'humorous' nature the artists wanted to convey, along with added ignorance of the sensitivity behind these portrayals. According to Karl F. Cohen, an animator by the name of Shamus Culhane remembers that during the early 1930s, most of the Fleischer studio members were unaware 
that their racist caricatures could be seen as offensive to some people (2013, p. 50). Only when the studio began to educate their staffs on what is seen as acceptable or otherwise, the staffs began to lessen their offensive humour. History has influenced these creators in accepting racist or offensive views due to the propagandist nature associated with these views that have continued on until after the war; it is the humane views these animators had of their fellow persons that they no longer caricaturized coloured people in a stereotypical manner, unless forced to by their studios. However, the sensitivity for others were thrown to the side during the war in the 1940s, as animator Myron Waldman "remembers deliberately drawing an offensive, bucktoothed caricature of a Japanese spy for the World War II propaganda short The Japateurs" (Cohen, 2013). In times of war, animations were abundant with these imageries to perpetuate the Japanese as inferiors and unlikeable in accordance to the propaganda. Animated films during the War era were spearheaded by the United States' Office of War, which worked with Hollywood studios in creating content in the war effort (Arnold, 2016, p. 110), thus the creation of these portrayals was made in an effort to influence the people to oppose the enemies. There is a continued portrayal of these images even after the war ended, thus cementing the stereotype of these characters until more modern times. After the war, with the involvement of the African American in the wars and in baseball leagues, some animators have gone to advocate for racial integration in their films. However, there are still people insisting on segregation and laughing over crude portrayals of racist caricatures. In Lehman's book, he mentions that "Hollywood animators found ways to preserve racial humour without attracting anti-stereotype activists" (2009, p. 104). While some have understood the implications that comes with the characterizations of these ethnic characters, some animators still choose to showcase these imageries on screen to entertain the masses when it can be done without such insensitive humour. During the Civil Rights Movement era, the cartoons shifted to something more anthropomorphic in nature, yet kept the racial and social conformity. In a Chuck Jones' "Looney Toons" episode, Martian Through Georgia, the story opens to a Martian trying to assimilate itself on Earth, and when he found out that the monster he had been hunting to appease the people there was in actuality himself, he chose to fly back to Mars where he was supposedly happier. In times of racial discourse and minorities fighting for their place within America, this particular short was unfortunately implying that by staying within the social conformity that has been placed, segregation could maintain balance and peace among the community. In Lehman's opinion, "The message is totally out of step with the support of a growing number of U.S citizens with the civil rights movement's push for racial integration" (2014, p. 17). Soon, the depiction of these caricatures trickled down, and there is not a single attributed or simple reason as how it came to be. Some of the studios chose to stop airing, distributing and even creating shorts with racist imageries due to the increasing awareness of the people towards racism in popular culture. Aside from that, the decrease of these portrayals could also be contributed by marketplace pressure as companies would not produce or distribute anything that would earn the ire of the public. Animations during that time were too expensive to produce even if the content was increasingly becoming popular, so companies were adamant on showing "positive" portrayals in order to gain more traction to the animated productions. However, in the 1970s, the avoidance of portraying African American images was violated when Ralph Bakshi released some of his controversial films such as Fritz the Cat (1972) and Coonskin (1975) despite having a black cast. In more modern animations, satirical and critical shows such as The Boondocks (2005-2014) which had a Black main cast, did not shy away with its social commentary and rage worn on their proverbial sleeves, and was never afraid to critique 
society (Maus \& Donahue, 2014, p. 23) despite some of the content becoming a topic of sensitivity of their white viewers even when the content was not directed for them.

African-Americans were not the only ones to have fallen victim to such portrayals, but many others have gotten the brunt of these racist characters, be it adopted into anthropomorphic characters or otherwise. Some of these were not due to the production company themselves but the people working within these companies, who chose to paint such characters without regards to future impacts their work will have on society. Isadore "Friz" Freleng was such one person, unable to communicate without either glorifying the characters meant to play the "good guys" or demonizing the antagonists. In the early years, during the Wars, he had poked fun on the Japanese soldiers in Bunny Nips the Nip (1944), portraying them as incompetent. The product of such portrayals did not necessarily fall onto the companies producing and distributing these contents, but also the animators who are insensitive to such discussions and are unable to properly discuss race in animation; an example that can be taken is Friz Freleng's inability to intelligently have a conversation in animation concerning race. In one of his race-themed animations D' Fightin' Ones (1961), he could have used satirical imageries to discuss the black-white tensions yet the animosity between the two animal characters did not extend beyond a terse "I hate you", thus avoiding from discussing this particular issue at the time of racial segregation. In fact, Freleng seemed to be avoiding or retreating from the issue by relying on his usual slapstick comedy. The Latinx portrayal have also suffered under Freleng's insensitive hands from their looks to accents as in Freleng's The Pied Piper of Guadalupe (1961), he relied on visual and verbal racial humour in developing Speedy Gonzales' character, a caricature of the Mexicans. Not only was Speedy seen talking with elongated vowels, mimicking that of the Mexican or Latinx minorities, but his nemesis, Sylvester, demeaned him in a racist manner once Speedy bested him. Due to an Academy Award nomination, this prolonged Speedy Gonzales' adventures and his continued derogatory Mexican imagery.

These issues however, were either not brought to light or have gone unnoticed due to the people's perception of it being highly innocent and would be without repercussions in the future. In Still \& Wilkinson's book, they've written that “... the overt racism that was initially a huge part of the beginning of the animated cartoon format would soon soften" (2019, p. 183). Not many were aware of such interpretation and characterizations could be seen as offensive in the future and some of the people who have commented on these issues have only searched for overt racism that could be seen as highly offensive during that time. Only when time has passed and people are becoming well-educated in the discussion of race and media, did these problems began to be noticed and nit-picked. These issues persist to even modern times, with the creation of both 'inclusive' animated media and more satirical ones. In 1993, there were still stereotypical portrayals of character, even in a major company such as Disney with their film, Aladdin (1993). The American-Arab Anti-Discrimination Committee asked Disney to alter portions of the film, as they had objected to the film's racist contents. While Disney met up with the members of the group, in the beginning, they had denied any racial slurs had been placed within the film. The president of the Committee, while happy of the changes made by Disney, the man admitted he was still upset over a line in the song which referred to the Middle East as "barbaric". Aside from that, Don Bustany of the Los Angeles chapter of the committee also mentioned that the supporting characters who were portrayed as nasty people, had foreign accents as opposed to characters Aladdin, Jasmine and the Sultan who spoke in an Americanized one. This has not been the first time Arabs were portrayed negatively in the media and have gone unnoticed, as Arab Americans have pointed out these 
imageries in cartoons "... that starred Woody Woodpecker, Bullwinkle and Johnny Quest" (Cohen, 2004). There are also portrayals in cartoons such as The Simpsons and Family Guy that has brought forth negative connotations; Apu Nahasapeemapetilon, an Indian immigrant from The Simpsons garnered major controversy due to the character's portrayal in his livelihood, accents and cultural portrayal. Apu is portrayed with a stereotypical Indian accent and worse more, he was voiced by a white, American voice actor. He was also portrayed as a convenience store employee, a stereotypical job for Indian or South Asian characters, despite his highly educated background. Being the few South Asian characters or even 'brown' character, Apu was seen as the token ethnic character that the show had to have to appease majority of their ethnic viewers. However, this particular problem was unresolved as the creators chose to be nonchalant and merely mentioned the issue in passing within the show, even when majority of Indian Americans vocalized their upset towards the character. This issue has shown that the problem relied in the creators and not the voice actor, as the voice actor for Apu, Hank Azaria have decided to step down from his role as the Indian character. Aside from that, creators are not entirely innocent, as time has shown that some would go even to the lengths of inserting racial stereotypes in villain characters, thus influencing how children or viewers perceive foreign people due to stereotypes such as accents, skin colour and even culture (Hoffman, 2014).

History as a whole has shaped the course of representations, through propaganda, ignorance and abuse, in entertainment which relied heavily on stigma and colonialization. The fault not only lies in the passage of time and wars, but also lies on the production studios and creators seeking to create such cartoons for the sake of entertainment and not for the betterment of society, clouded by their viewpoints against the minorities. At the end of the day, those who sought to gain from such caricatures continue to do so without regards to the people that could and will be affected by these portrayals in the name of profit.

\section{The People as the Voice of the People}

Unlike the representations of the past, the representations of races today have made a complete turnaround when compared to prior animations. These changes were made for the people by the people, in an attempt to correctly portray cultures and races in a more positive manner. In this section, there is an exploration of positive representations created by an array of animators, creators and studios, and animations with these representations will be focused on in the discussion as well as the reasoning behind the creation of these shows.

The improvement of racial representation in Western animation was by the people; specifically, the animators and creators who were not only striving for diversity but also socially and racially aware of the lack of representation within the media itself. This began in the 1970s, where a slew of insensitive media had littered the Western animation industry. Shows such as The Jackson Five, The Harlem Globetrotters as well as Bill Cosby's Fat Albert and the Cosby Kids were a source of black-pride for many black Americans growing up in the States, especially during a time where segregation was at large during the Civil Rights Movement, where the black-white tensions were at a high due to the fight for equal rights amongst the people. Some characters or even shows have taken an aspect of the race, such as the blacks' love for singing and performance, twisting it to be a prevalent stereotype from the acts of black minstrelsy in the past. However, some of these portrayals, while stereotypical, have shown that what was once seen as negative could be a source of ethnic or cultural pride, just by changing not only the perspective of the portrayals but showcasing a more positive outlook on the issue; instead of portraying black characters as lazy by having 
them singing and dancing, some creators opted to showcase these characters doing such merriment during breaks, gatherings and overall, having a love for their own craft and culture that could have been lost had they not held onto such 'frivolous acts' as the colonizers would have people believe. These aspects of race and culture have been claimed back by the minorities to empower and encourage themselves to embrace their culture and upbringing, their race or skin colour and have the social awareness that by keeping these cultural nuances close to their hearts, they could continue on appreciating and living their own lives, rather than the lives forced upon them.

In much modern animations, these racial representations, especially positive ones have become a challenge of its own. One such challenge is Disney's Aladdin (1993) where Princess Jasmine's character, while seen as Arabic, do not exactly exhibit a wholly Arabic portrayal and more so leaned towards the Westernizers' sexualisation of Arabic women or belly dancers that are prevalent in prior Middle-Eastern women representations. Despite the somewhat sexualization of Jasmine's character, Jasmine herself was portrayed unlike many stereotypical Arab women; instead of being meek and submissive, she was feisty and fought for her own rights. She was not afraid to raise her tone against the likes of her father, a Sultan or even Jaafar. She was someone that a majority of Middle-Eastern women and many others could look up to as a role model in terms of her personality and self-worth. With Mulan (1998), the main character, Hua Mulan was one of Disney's beloved princesses, someone anyone could relate and respect. Adapted from a Chinese legend, the character was a strong, independent woman who sought to replace her father's place as a soldier. She was strong, courageous, yet still maintained aspects of her femininity all the while fighting with fellow soldiers. Mulan, in a way, inspired women and even men to take pride in being Chinese or Asian, acting as a role model for Asian children, regardless of their actual heritage and culture. This continued on with the creation of Tiana, Disney's first black princess from The Princess and The Frog (2009); Tiana was a Southern belle with charm, grace, and most importantly, an ambition that has never deterred throughout the film. She was the black girls' role model, from her independence to her spirit regardless of her race and gender despite the film being supposedly set in the 1920s, an era where those two aspects of the character would be condemned (King et al., 2010,). However, with many racial representations, it also came with its own difficulties as some will always find something to pick on, some of which is Tiana's love interest, "Prince Naveen not being black enough" or that through the majority of the film's screen time, "Tiana's character was... a frog" (Howe \& Yarbrough, 2014, p. 181). While all of this certainly could raise the issues on proper representations, these issues could be seen as insignificant throughout the film; it was established that Prince Naveen was not blackborn but was perhaps South Asian-born instead. Tiana's transformation was also not due to the company's refusal to animate black women, but was mostly done to accommodate the storyline they had planned prior to the production of the movie. However, not all of Disney's contemporary animated films garnered such high praises like the aforementioned films above, as Disney's Native American-focused film, Pocahontas (1995) received some backlash concerning the story it told to the audience. In an Encyclopaedic book by Arnett, fellow contributor, Avi Santo wrote, “Disney's Pocahontas (1995) was accused of whitewashing Native American history, ignoring historical atrocities while rendering Pocahontas as an Indian Barbie doll" (2007, p. 148). In this situation, the story was heavily edited from the actual historical accounts, as it did not particularly fit Disney's image as a family-friendly animation studio. While the film had its controversies, one could see Pocahontas as Disney's starting point of creating more wholesome and inclusive content, with it being the drive of the 
detailed research that has appeared and done in more recent minority-centric films that have come after. In fact, Disney in itself has claimed and warn viewers of their more outdated 'cultural depictions' in their animated works, and while some may see the wordings used as dismissive, this was one of the few times the company took accountability (Iati, 2019, www.washingtonpost.com). Aside from that, the Pocahontas controversy has also shown that the audience are now media savvy and are very much conscious of the racial inequalities that have presented itself in the medium of Western animation.

Aside from these Disney films, some television shows have also decided to create a more diverse cast of characters, from Disney animations such as American Dragon Jake Long (20052007) which showcased an Asian American family steeped with Chinese culture, as well as The Proud Family (2001-2005) and Fillmore! (20022004), two cartoons that have black family and children respectively as their main focus of the show. Not only was Disney one of the more diverse-inclusive studios, but one of their competitors, Cartoon Network was one of the few studios popularly known for their unique animated shows and their social awareness of the content they put out. In Jason Mittell's book, he wrote, "Cartoon Network acknowledges much of their audience in children, refraining from showing more controversial racial representations, war era propaganda shorts..." (2004, p.86). Cartoon Network seek to present audience, be it their children or adolescent demographic, or even their small percentage of adult viewers, cartoons that were not only fun but also animations with an array of inclusive casts such as in Ed, Edd' $n$ Eddy (1999-2008), Samurai Jack (2001-2004), The Life and Time of Juniper Lee (2005-2007) and many others. These representations serve to be some of the pioneers for more recent animations to take charge in creating different characters with more diverse backgrounds, representations, ethnicities and even culture, especially ones created and developed in their studios specifically.

These modern shows place an importance in positive representation, showcasing different sides to characters and allowing the general public to connect with these characters more. A majority of black characters were previously shown to be rough and tough but more recent animations have showcased black men as sensitive and great role models to kids as opposed to some of medias' more toxic portrayals of such coloured men in the lives of their children. Black men have also been historically shown to be sports-oriented, but in shows such as Static Shock (2000-2004), The Proud Family (2001-20015), The Jellies (2017-2019) and even the most recent one yet, Craig of the Creek (2018-2019), we see black men and black boys being nerdy, dramatic and even emotionally vulnerable to themselves and to others. Aside from that, Asian and Latinx characters have also seen a change in representations as well. In the past, a majority of Asian representation were either Japanese or Chinese and sometimes, the ethnicities of certain Asian characters were considered vague; however, there has been an increase of recognizable Asian representations aside from the aforementioned two, ranging from fellow East Asians such as Koreans to more South of Asia, such as characters from the Middle East and India. Latinx characters have also seen some positive representations, such as in children-focused animated shows such as the Dora the Explorer series (1999-2019), El Tigre (2007-2008), The Book of Life (2014) and most recently, Coco (2017), to the more teenage or adult focused animations, with representations ranging from pure Latinx character such as The White Tiger from The Ultimate Spiderman (2012-2017) to mixed heritage character like Miles Morales from the same series. There has also been positive representation of even minor races such as in Moana (2016) which showcased the cultural aspect of the Polynesian people and their beliefs. 
These representations were not just because of a studio's haphazard decision to bank in on diversity for more profit, but these works were particularly crafted by both minority creators and non-minority creators to allow the once-condemned and stereotyped races to have something whole-heartedly their own. These shows and characters were created for the people by the people wishing that their shows would be able fill hearts that have been hurt by insensitive portrayals that only served to increase prejudice and racist beliefs against other people of colour. In Disney films, the studio and importantly, its animators, tries their best to place the idea of humanity in its forefront; much like in The Princess and the Frog, "the beginning of the movie lays the ground for Disney's main message: that blacks are decent, honourable, loving and hardworking people, and that there is something of value that can be learned from black culture" (Mask, 2012). While Disney has been criticized for its supposed portrayal leaning more towards multiculturalism which were politically correct or perhaps even a sense of diversity without inclusion (Roberts, 2020), the company's continued representation has benefitted the marginalized audience in some capacity. Some creators may not have known that their works could also have positive racial representation; in the 90 s to the 2000s, animation have shown a more diverse cast besides their white main character, and normalizing these characters' existence within the story, such as the cast of $E d$, Edd ' $n$ Eddy (1999-2008) and Codename: Kids Next Door (1998-2008) which had an array of child characters from different races and cultures. Some animations strive to have a representation such as The Proud Family with black characters as their majority with fellow Hispanic and Caucasian characters in the mix or in The Life and Times of Juniper Lee which has a more Asian-focused cast. Recent creators have also tried to have these representations even in anthropomorphic-majority shows such as Korean or Korean-speaking characters in We Bear Bears (2015-12019) and Adventure Time (2010-2018) respectively. Shows such as Steven Universe (2013-2019) and Craig of the Creek have a large array of ethnic characters of different backgrounds, with mixtures of Caucasian, African Americans, Asian and Latinx characters, and these shows are created and curated with the intention of allowing not only kids but also some percentage of adults enjoying animated shows to feel represented and see themselves realized on screen. Ben Levin, one of the creators of Craig of the Creek has said, "We saw first-hand [working on Steven Universe] how much representation mattered to people and how important it is for people to feel seen. And so, when we had the opportunity to create a show, we wanted to make something fun that the kids would love but would also have a positive impact" (Ifeanyi, 2018, www.fastcompany.com). These creators are aware of the positivity of such representations, and as the people, they wanted to see more of these portrayals on screen to the benefit of the people as well. With that, these animators and creators, along with their diverse writing and production team have created works with the intent to allow and encourage the audience to have pride in their ethnicity to the benefit of the cultural and social awareness for the generations to come.

\section{The Importance of Racial Representation in Western Animation}

With the change of the flow and in relation, the portrayals of racial characters, there is an importance behind the representations that have been shown throughout time and history, both in the good and the bad. In this section, I will outline the significance of having such representations and why the erasure of past representations may not necessarily open a path for present portrayals people have seen today.

The multitudes of representations present in the animated works mentioned in the previous topics have had impacts and effects to the audience, be it consciously or 
otherwise. While a majority of these representations have effects on the audience of colour, it is not to say that these representations do not influence society's continued perception of them as well. Every representation shown and put on screen can impose and alter perspective and ideologies towards people no matter the content of said representations; each depiction shapes the audiences' mind and beliefs and this can be somewhat positive or negative given the context behind every characterization. Both 'bad' and 'good' representation has its place in animation history and hold importance as it will continue to define and mould future characters whether new creators choose to continue on with the trend or change it. Portraying racial characters can also become a tool to shape audience and perspective, altering beliefs and in some sense, their own realities to better fit what they see on a regular basis. 'To see is to believe' is a quote that is used constantly in the English vernacular and can be a double-edged sword; even through animation, the characters can modify and influence the thoughts and perception of society towards people. Animated entertainment can influence and affect people's view of the world via stereotypes and skewed portrayals, along with the underrepresentation certain minorities face (Danesi, 2013, p.98). Children and in some cases, even adults are prone and vulnerable to these portrayals shown on screen and through belief and visualisation, the images seen can either push a culture or race into a positive light, or condemn a group to a life of discrimination and bigotry.

To begin with a look into older animations, the early representations of people of colour were considered less than desirable, as these portrayals were racist in nature and served to fuel propaganda, justify deaths and to drive white Americans or all Americans into racial segregation or war. Furthermore, when the cinematic were culled for a more "appropriate" animation targeted for children television, the lack of inclusion of racial portrayals led to a whiter aesthetic (Banet-Weiser, 2007, p. 149). However, while these representations in past animations paint an undesirable outlook on people of colour when compared to their real-world counterparts, one cannot simply deny the existence of these works or erase them from history and the minds of people. While there is no denying that these animated works have caused and can continue to cause hurtful ideologies and assumptions towards people coming from more ethnic backgrounds, these animations have done their due and are now considered an incorrect portrayal of race and ethnicity. Instead, these animated works should be taken and treated as a constant reminder of the tasteless views that should not be mirrored in the current era or the upcoming future as the message and visuals of these animations can have detrimental impact that could continue to affect the people in the future. As mentioned before, children and adults can fall victim to falsehoods and misinformation shown in media, no matter the type; people tend to believe more if they see it more. The act of seeing something so constantly to the point of actually thinking and believing they are factual and based in reality is called the Illusory Truth Effect, in which it is "a mental error that causes us to perceive something to be true when we hear it repeated frequently and persistently" (Tsipursky \& Ward, 2020). The Illusory Truth Effect in a way, relates back to a theory by Gerbner (2002) called the Cultivation Theory in which shows aired on television are consumed repeatedly, thus planting the imageries they have seen to become a reflection of reality (Signorelli, 2005, p. 19). These theories, while not mentioned, appeared in studies conducted by TuftsNow (2018) and The Opportunity Agenda (2011) which investigated and study children and adults who have viewed themselves in shows and detect the altered perception they have for their communities or themselves based on the racial representations shown to them (www.opportunityagenda.org). Aside from that, viewers who consume content heavily, and therefore, exposed to skewed images and portrayals may likely 
grow to believe the stereotypes to be reality (Luther, Lepre \& Clark, 2017). Therefore, these animations should be used as education tools to enlighten children and future generations of the falsehoods people from different races have faced and may continue to face if there is ignorance and apathy in the minds of people creating them or consuming them. In animation, while it is not necessarily clear whether negative stereotyping and the accompanying discrimination targets minority children but it cannot be said that these biases do not affect children, whether it be directly or not (Loeber \& Farrington). Some may argue that these works should be erased and should not be shown to preserve the minds of children from horrific portrayals.

According to Dobrow, Gidney and Burton, "there is a relationship between low selfesteem and negative media portrayals of racial groups, in addition to an association between poor self-esteem and the paucity of portrayals of a particular group" (2018, now.tufts.edu). However, the erasure of these works may cause more problem than good as the existence of these works have shaped animation today; more people of colour are entering and diversifying the animation industry along with white allies trying to include more diversity into their works. The existence of past animations ensure that newer creators can look to the past and either adopt the better parts of it or disregard the negative aspects of the representations shown. Aside from that, any kind of representation, no matter good or bad is better than none as Toby Miller says, "representation in the fictional world signifies social existence; absence means symbolic annihilation" Mughal, 2019). Even with the negative representations given in the past animated works that may bring forth lies and bigotry, the total lack of representation erases the existence of these race, ethnicities and cultures altogether from society.

Modern day animations' depictions of race and culture plays a different significance in the lives of the viewers; they act as modern-day representatives to the diverse society we have today. These shows in majority, mirror the everyday people and interactions with their fellow neighbours and community members. While psychological theories such as the Illusory Truth Effect and the Cultivation Theory are often used to discuss negativity of consuming false information and 'brain-dead' media that can result in the distortion of reality for some viewers, there is nothing to say about using these theories to benefit the people instead; the hope behind the creation of newer racial portrayals and their inclusion in more diverse and engaging stories is that with enough positive representation and educated content about people of colour, not only acceptance and tolerance towards people who differ in skin tone might increase, but also alter the discriminatory views some people have against people who differ in race. Shows such as Fat Albert and the Cosby Kids has taught their viewers about the truths behind race-related issues or misconceptions in an attempt to assuage rumours and falsehoods some may have against other races. One of the storylines told disproved the myths people believed about indigenous people in America, after countless of other shows made accusatory claims about the Native's beliefs and culture. This highlights that even in the era where racial segregation, racism and bigotry was possibly higher than that of today's, some shows had the ability to take a conscientious move and change a person's view towards an entire race or culture with just the right amount of education and charisma, ensuring the show's continued popularity with both white and non-white audience. In addition to that, these newer shows allow children and even adults to have reassurances about themselves by seeing people similar to their own, acting in similar fashion or even perhaps being the main character of their own stories, then feeling empowered and confident in expressing and taking pride in their own communities and history. As mentioned before, studies conducted by TuftsNow and The Opportunity Agenda delves into the psyche of both children and adults 
who have watched shows with their racial representations and found that negative representations may affect how these children and adults see themselves. With enough positive representation, self-esteem and respect can be built within people of colour, and negative impacts such as self-hatred or the concept of being racist against your own race could one day be obsolete. Psychologist Sheryl Brown Graves noted that the portrayals in the media influenced children's perception of other races and their own, such as Black children's positive or negative attitude triggered by the Black characters they had seen (Wilson et al, 2012). Hence, newer animation should use the animation of the past as a guideline to guarantee that these animations will not once again become the norm, and instead, become a whisper in the sea of progress. By taking steps forward and only looking to the past as what it is; a thing of the past, the probability for the bigoted views and discrimination towards other races would decrease. Especially for children, who are raised to fit the mould they have of the world, even if their parents or the people around them hold these derogatory views, the chance for them to realize the truth and accept their fellow community members without contempt could change the world into a better place by disregarding the differences. Children tend to look up to role models in the media that they view and would even go as far as to emulate the actions seen on television, be it done by actors or even cartoon characters (Mazzarella, 2007). Having examples set by these characters in the media they constantly consume, can change the path set for these children into something much more beneficial and humane, instead of condemning them to a life of racial profiling. By taking strides into improving the lives of these people just through media alone, these representations that matter has helped a number of children and even adults to feel validated and have a sense of belonging in a community that once had no place for them in the past.

\section{Conclusion}

In conclusion, this paper is an exploration of the history of racial representation in Western animation and the efforts taken by animators to increase the numbers of such representation in the animation industry in the states along with the importance of having these representations. First, an investigation of the history of racial representation in Historical Context of Racial Representation in Animation was done, where the focus of the sub-topic was the issues pertaining to representation in animation and the historical influence the representations have gone through and evolved. Then, in The People as the Voice of the People, there was an exploration of the array of animation and the racial representation that exists in those animated shows, as well as the reason behind the fruition of such representations in the animation industry today. Therefore, in The Importance of Racial Representation in Western Animation, further discusses these issues and outline the significance of having racial representations in animated works. Furthermore, a realization has been made that the lack or even misrepresentation of ethnic minorities in Western animation, specifically in the American animation industry was influenced heavily through their historical timeline and the movements these minorities have gone through or have become witnesses of. It became obvious that the prejudices of the past have heavily shaped the racially charged stereotypes the people have been accustomed to see as entertainment, along with the lack of intelligent discussion on the racial tensions that have existed and, in some way, have continued to exist even in these modern times. The reason why these representations have drastically changed today was due to the people who decided that they no longer wanted to see those content in more supposedly integrated and tolerant eras, and instead chose to show the audience what they deem is more appropriate to the times. 
However, the erasure or complete disregard of past animations should not take place as these representations along with modern depictions both have an importance in shaping the industry and shows to come.

Besides, in terms of the production of animations with racial representation, an investigation into the history to study whether the influx of racist portrayals was due to the production company's influence or was due to the animators with less than savoury perspective against minorities. The issue behind that large amount of racist portrayals did not necessarily fell on the company and animators, as subjects such as war and propaganda have influenced these portrayals. However, this did not implicate productions and creators were innocent; far from that, some choices made were due to ignorance or a superiority complex against the minority because of their upbringing, and some were made to preserve the business of these productions as the animations with those portrayals had done well among the audience. However, throughout the flow of time, as people learn about stereotypes, racism and become more aware socially and culturally, the negative racial representation could now be seen as it truly was; problematic and horrific in nature.

All in all, these racial representations and its growth says something about the reality behind this; the initial overt racism and the continued subtlety of stereotypes in these representations were due to the influences of the past that have carried on to the future. These acts of micro-aggressions towards the minority was the result of propaganda, colonializations, superiority complex and most damning of all, ignorance towards the people from these ethnic minorities. As Rodney Spivey-Jones once highlighted, "society disfigures the personhood of marginalized people" (Botstein \& Novick, 2019). Through actions, there exists consequences and unfortunately, those who are considered the minorities have been the brunt of these consequences. This conclusion has been reached due to the slew of information gathered, and the connectivity of insensitive portrayals to the socio-political movements that have gone through America as a country and to its people. However, the changes of these portrayals were due to none other than the people who have wished for change and have worked towards it, bringing forth more positive representations for coloured people during times where it seemed that these cartoons would go forth and continue to portray negative aspects of the minorities. It is due to the efforts, racial and social awareness of modern creators not only in normalizing minority portrayals, but in animated shows where they have now become the focus instead, allows the audience of multiple races to enjoy something that refreshingly and positively impact them and the views people will have of them in the future. Through this change in the animation industry, it is established that both aspects of representation despite being considered negative or positive, have a significance in moulding animation today. By understanding the history of racial representations and the people behind empowering representations along with its importance, we allow ourselves to be more open-minded individuals, in accepting and outputting characters from multitudes of backgrounds, regardless of race and appearance, and in the future perhaps, including the aspects of religion, sexuality and other labels us humans have grown accustomed to place and embrace. 


\section{References}

Arnett, J. J. (2007). Encyclopedia of children, adolescents, and the media. SAGE.

Arnold, G. B. (2016). Animation and the American imagination: A brief history. ABC-CLIO.

Banet-Weiser, S. (2007). Kids rule!: Nickelodeon and consumer citizenship. Duke University Press.

Botstein, S., \& Novick, L. (2019). Ken Burns Presents: College Behind Bars [Film]. Skiff Mountain Films.

Cohen, K. F. (2013). Forbidden animation: Censored cartoons and blacklisted animators in America. McFarland.

Danesi, M. (2013). Encyclopedia of media and communication. University of Toronto Press.

Dobrow, J., Gidney, C., \& Burton, J. (2018). Cartoons and stereotypes. Tufts Now. https://now.tufts.edu/articles/cartoons-and-stereotypes

Dobson, N., Roe, A. H., Ratelle, A., \& Ruddell, C. (2018). The animation studies reader. Bloomsbury Publishing USA.

Hodkinson, P. (2017). Media, culture and society: An introduction (2nd ed.). SAGE.

Hoffman, E. (2014). Magic capes, amazing powers. Google Books. https://books.google.com.my/books?id=IHNFCgAAQBAJ\&source=gbs_navli nks_s

Howe, A. N., \& Yarbrough, W. (2014). Kidding around: The child in film and media. Bloomsbury Publishing USA.

lati, M. (2019). Disney Plus warns of 'outdated cultural depictions' in some films. That's not enough, experts say. The Washington Post. https://www.washingtonpost.com/artsentertainment/2019/11/13/disney-pluswarns-outdated-cultural-depictions-somefilms-thats-not-enough-experts-say/

Ifeanyi, K. (2018). Inside cartoon network's racially groundbreaking show "Craig of the Creek". Fast Company. https://www.fastcompany.com/40551963/inside-cartoon-networksraciallygroundbreaking-show-craig-of-the-creek

King, C. R., Lugo-Lugo, C. R., \& Bloodsworth-Lugo, M. K. (2010). Animating difference: Race, gender, and sexuality in contemporary films for children. Rowman \& Littlefield Publishers.

Lehman, C. P. (2009). The colored cartoon: Black representation in American animated short films, 1907-1954. University of Massachusetts Press.

Lehman, C. P. (2014). American animated cartoons of the Vietnam era: A study of social commentary in films and television programs, 1961-1973. McFarland.

Loeber, R., \& Farrington, D. P. (2000). Child delinquents: Development, intervention, and service needs. SAGE.

Luther, C. A., Lepre, C. R., \& Clark, N. (2017). Diversity in U.S. mass media. John Wiley \& Sons. Mughal, H. A. (2019). Support at Work and its Relationship with Employee Performance: Critical Insights for Early Scholars. Annals of Contemporary Developments in Management \& HR (ACDMHR), 1(3), 16-21.

Mask, M. (2012). Contemporary Black American cinema: Race, gender and sexuality at the movies. Routledge.

Maus, D. C., \& Donahue, J. J. (2014). Post-soul satire: Black identity after civil rights. Univ. Press of Mississippi.

Mazzarella, S. R. (2007). 20 questions about youth \& the media. Peter Lang.

Miller, T. (2003). Television: Critical concepts in media and cultural studies (Vol. 2). Taylor \& Francis. 
Mittell, J. (2004). Genre and television: From cop shows to cartoons in American culture. Psychology Press.

Roberts, S. (2020). Recasting the Disney princess in an era of new media and social movements. Lexington Books.

Sammond, N. (2015). Birth of an industry: Blackface minstrelsy and the rise of American animation. Duke University Press.

Signorielli, N. (2005). Violence in the media: A reference handbook. ABC-CLIO.

Still, J. M., \& Wilkinson, Z. T. (2019). Buffy to Batgirl: Essays on female power, evolving femininity and gender roles in science fiction and fantasy. McFarland.

Topos Partnership. (2011). Media representations and impact on the lives of Black men and boys. The Opportunity Agenda.

https://www.opportunityagenda.org/explore/resources-publications/socialscienceliterature-review

Tsipursky, G., \& Ward, T. (2020). Pro truth: A practical plan for putting truth back into politics. Changemakers Books.

Wells, P. (2013). Understanding animation. Routledge.

Wilson II, C. C., Gutierrez, F., \& Chao, L. (2012). Racism, sexism, and the media. SAGE. 